\title{
Review
}

\section{Regulation of CD95/Fas signaling at the DISC}

\author{
IN Lavrik ${ }^{1}$ and PH Krammer ${ }^{\star, 1}$
}

CD95 (APO-1/Fas) is a member of the death receptor (DR) family. Stimulation of CD95 leads to induction of apoptotic and nonapoptotic signaling pathways. The formation of the CD95 death-inducing signaling complex (DISC) is the initial step of CD95 signaling. Activation of procaspase-8 at the DISC leads to the induction of DR-mediated apoptosis. The activation of procaspase8 is blocked by cellular FLICE-inhibitory proteins (c-FLIP). This review is focused on the role in the CD95-mediated signaling of the death effector domain-containing proteins procaspase-8 and c-FLIP. We discuss how dynamic cross-talk between procaspase-8 and c-FLIP at the DISC regulates life/death decisions at CD95.

Cell Death and Differentiation (2012) 19, 36-41; doi:10.1038/cdd.2011.155; published online 11 November 2011

Facts

- $\operatorname{CD} 95$ (APO-1/Fas) is a member of the death receptor (DR) family

- CD95 stimulation leads to the formation of the CD95 deathinducing signaling complex (DISC).

- Procaspase-8 is activated at the DISC leading to the induction of both apoptotic and non-apoptotic pathways.

- Cellular FLICE-inhibitory proteins (c-FLIP) isoforms: c-FLIP

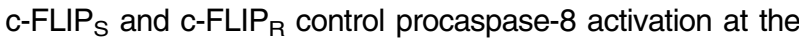
DISC.

\section{Open Questions}

- The exact mechanism of CD95-mediated non-apoptotic signaling is not established.

- The stoichiometry of the CD95 DISC is a question of future studies.

- New molecules may be found to be associated with the DISC.

\section{CD95 Signaling}

CD95 (also called APO-1; Fas; fas antigen; tumor necrosis factor receptor superfamily member 6, TNFRSF6) is a member of the DR family, a subfamily of the tumor necrosis factor receptor superfamily. ${ }^{1}$ All members of the DR family are characterized by a cytoplasmic region termed death domain (DD). ${ }^{2,3}$ DD are 80-100 amino-acid long motifs involved in the transduction of the apoptotic signal. Crosslinking of CD95 with its natural ligand (L), CD95L (CD178) ${ }^{4}$ or with agonistic antibodies such as anti-APO- $1^{5}$ induces apoptosis in sensitive cells.

Stimulation of CD95 has been also reported to trigger nonapoptotic pathways. ${ }^{6-12}$ However, details of CD95-mediated non-apoptotic pathways remain largely unknown. Importantly, it has been shown that membrane-bound CD95L is essential for the cytotoxic activity, whereas soluble CD95L appears to promote autoimmunity and tumorigenesis via induction of non-apoptotic pathways, in particular NF- $\kappa \mathrm{B} .{ }^{13}$ Future studies should elucidate more details on the mechanism of nonapoptotic action of CD95L.

Binding of CD95L or agonistic antibodies to CD95 leads to formation of a receptor complex at the cellular membrane, which was named DISC. ${ }^{14}$ The DISC consists of oligomerized receptors, the DD-containing adaptor molecule FADD/MORT1 (Fas-associated DD), procaspase-8 (FLICE, $\mathrm{MACH} \alpha, \mathrm{Mch} 5)$, procaspase-10 and the c-FLIP (Figure 1). ${ }^{15-17}$ The interactions between the molecules at the DISC are based on homotypic contacts. The DD of the receptor interacts with the DD of FADD, whereas the death effector domain (DED) of FADD interacts with the $\mathrm{N}$-terminal tandem DEDs of procaspases-8, -10 and c-FLIP. As a result of DISC formation procaspase-8 is activated at the DISC resulting in the formation of the active caspase-8, which leads to apoptosis.

The initial events of DISC formation have not been clarified yet. Pre-oligomerization of CD95 via the pre-ligand assembly domain has been reported to have an important role in apoptosis initiation. ${ }^{18}$ Recently, there have been several new reports on the X-ray structure of the complex formed by isolated CD95 and FADD DDs. ${ }^{19,20}$ Scott et al. ${ }^{19}$ have suggested that binding of CD95L leads to an opening of the CD95 DD, which exposes the FADD-binding site and simultaneously generates a bridge between two CD95 molecules. They show that a basic unit of this oligomeric CD95 network is composed of a tetramer, comprising four FADD DDs and four CD95 DDs. In contrast, Wang et al. ${ }^{20}$ have reported that a basic unit of the CD95 DISC comprises

${ }^{1}$ Division of Immunogenetics, Tumorimmunology Program German Cancer Research Center, Heidelberg, Germany

${ }^{*}$ Corresponding author: PH Krammer, Division of Immunogenetics, Tumorimmunology Program German Cancer Research Center, Im Neuenheimer Feld 280,

Heidelberg D-69120, Germany. Tel: + 4962214 23718; Fax: + 4962214 11715; E-mail: p.krammer@dkfz.de

This article is dedicated to Jürg Tschopp.

Keywords: CD95; caspase-8; apoptosis; C-FLIP; DISC

Abbreviations: DISC, death-inducing signaling complex; C-FLIP, cellular FLICE-inhibitory proteins; cyt $C$, cytochrome $C$

Received 06.7.11; revised 24.8.11; accepted 27.9.11; Edited by G Melino; published online 11.11.11 


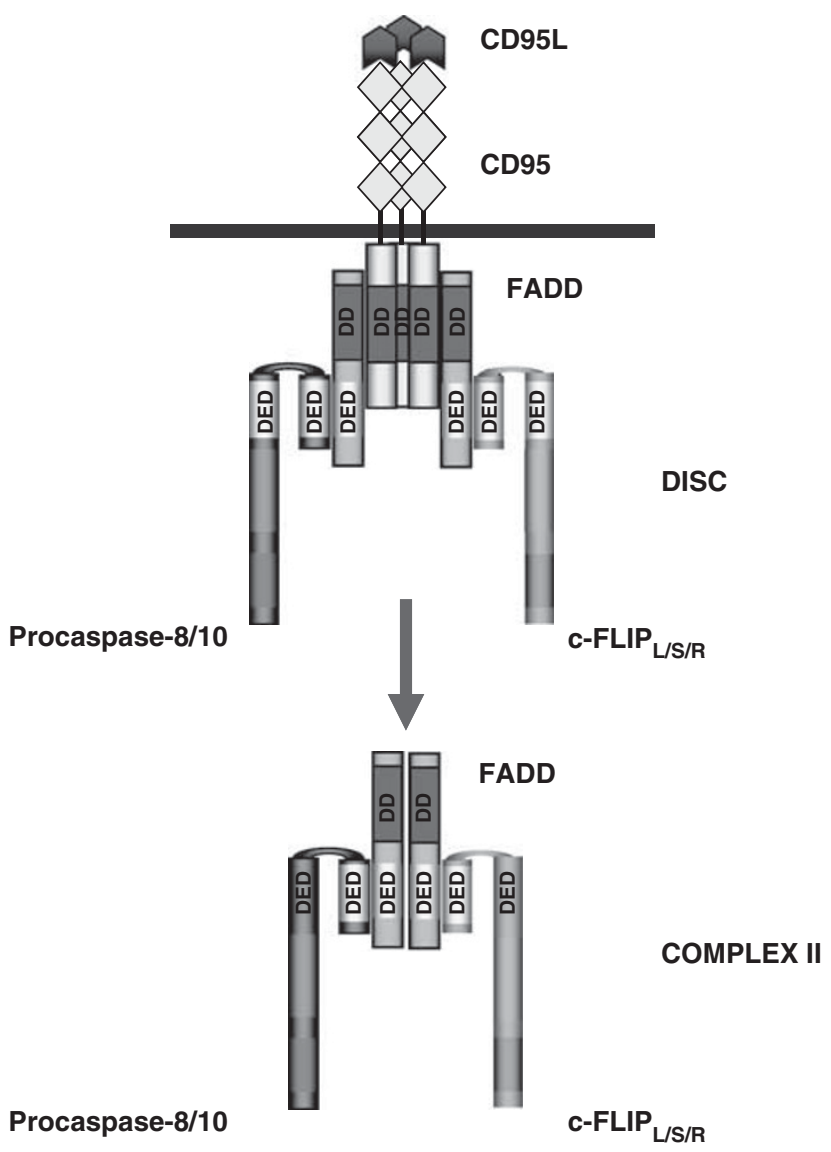

Figure 1 The CD95 DISC and complex II. The DISC consists of CD95 (depicted in yellow), FADD, (depicted in light blue), procaspase-8/procaspase-10, (depicted in green) and c-FLIP (depicted in violet). Complex II comprises FADD, procaspase-8/10 and c-FLIP. DD are shown in red; DED are shown in light yellow. The interactions between the molecules at the DISC and complex II are based on homotypic contacts. The DD of CD95 interacts with the DD of FADD while the DED of FADD interacts with the N-terminal tandem DEDs of procaspase-8, procaspase10 and c-FLIP. The color reproduction of this figure is available at the Cell Death and Differentiation journal online

5-7 CD95 DDs and 5 FADD DD. The reported X-ray structures contradict each other with respect to the CD95/ FADD complex; nevertheless, they provide a basis for a model of DD interactions at the DISC leading to procaspase-8 recruitment and activation. Certainly, the future challenge should involve obtaining the X-ray structure of the CD95 DISC assembled from the full-length CD95, FADD and procaspases, which would provide further insights into the structure of the complex.

In the CD95 apoptotic pathway two types of cells and signaling pathways have been established. ${ }^{21}$ Type I cells are characterized by high levels of CD95 DISC formation and high amounts of active caspase-8. Activated caspase-8 directly leads to activation of downstream effectors caspases-3 and -7. In Type II cells, there are lower levels of CD95 DISC formation and, thus, lower levels of active caspase-8. In this case, signaling might require an amplification loop. This amplification loop involves the cleavage by caspase-8 of the Bcl-2-family protein Bid to generate truncated (t)Bid and subsequent bid-mediated release of cytochrome $C$ (cyt $C$ ) from the mitochondria. The release of cyt $C$ from the mitochondria results in apoptosome formation followed by the activation of procaspase- 9 , which in turn cleaves downstream effector caspases-3, -6 and -7. Importantly, it has been shown that Bid is essential for CD95induced apoptosis in hepatocytes but dispensable in thymocytes. $^{22,23}$ This indicates that CD95-mediated signaling in thymocytes can be considered as Type I, while hepatocytes can be classified as Type II cells. In addition, an important role of XIAP in the amplification of Type I signal has been reported recently. ${ }^{24}$ Jost et al. ${ }^{24}$ have shown that the levels of XIAP expression can define Type I versus Type II signaling in a particular cell. They have demonstrated that BID/XIAP double-deficient mice are sensitive to CD95-induced apoptosis, whereas BID-deficient mice typically survive injection with CD95L or anti-CD95 antibodies.

Recently, we and others have shown that there is a second CD95 signaling complex formed upon CD95 stimulation, which was termed as complex II. Complex II comprises DEDproteins FADD, procaspase- 8 and C-FLIP, and does not contain CD95 (Figure 1). ${ }^{25,26}$ Complex II is formed within minutes after receptor stimulation. Apparently, complex II contributes to the activation of caspase-8. However, the amount of procaspase-8, which is activated in complex II versus in the DISC, and the mechanism of CD95 complex II formation remain unclear. ${ }^{25}$ Notably, the formation of a second complex was first discovered in TNF signaling for TNFR1 in Jürg Tschopp laboratory in 2003. ${ }^{27}$ Complex II in TNFR1 signaling does also not contain the receptor itself but comprises all the other components of the TNFR1 complex, for example TRADD, receptor-interacting protein 1 (RIP1), TRAF2 as well as the apoptosis-inducing components FADD, caspase-8 and caspase-10. In TNFR1 signaling, the generation of complex II has an essential role in caspase- 8 activation and apoptosis induction. The formation of complex II was reported to be a characteristic feature of a number of TNFR family members including TRAIL-R1/R2 and CD95. ${ }^{25,28}$ Therefore, the formation of complex II can be considered as a universal paradigm of TNFR signaling.

CD95 pro-and anti-apoptotic signaling is regulated at multiple levels: at the DISC, at complex II and at the mitochondria. Procaspase-8 and c-FLIP are two DED proteins, which are essential for the initiation of the apoptotic and non-apoptotic signals at the CD95 DISC. Below we describe in detail the DED-proteins procaspase-8 and c-FLIP, and the mechanism of their pro- and anti-apoptotic action.

\section{Procaspase- 8 and its Activation at the DISC}

Procaspase- 8 belongs to the family of caspases. Procaspase8 is activated at the DISC. ${ }^{29}$ Two isoforms of procaspase- 8 (procaspase-8a and procaspase- $8 \mathrm{~b}$ ) were reported to be bound to the DISC. ${ }^{30}$ Procaspase- $8 \mathrm{a} / \mathrm{b}$ possess two tandem DED domains as well as the catalytic subunits p18 and p10 (Figure 2). Procaspase-8a contains an additional $2 \mathrm{kDa}$ (15 aa) fragment, which results from translation of exon 9. This small fragment is located between the second DED and the large catalytic subunit resulting in the different length of procaspase-8a (p55) and procaspase-8b (p53). 

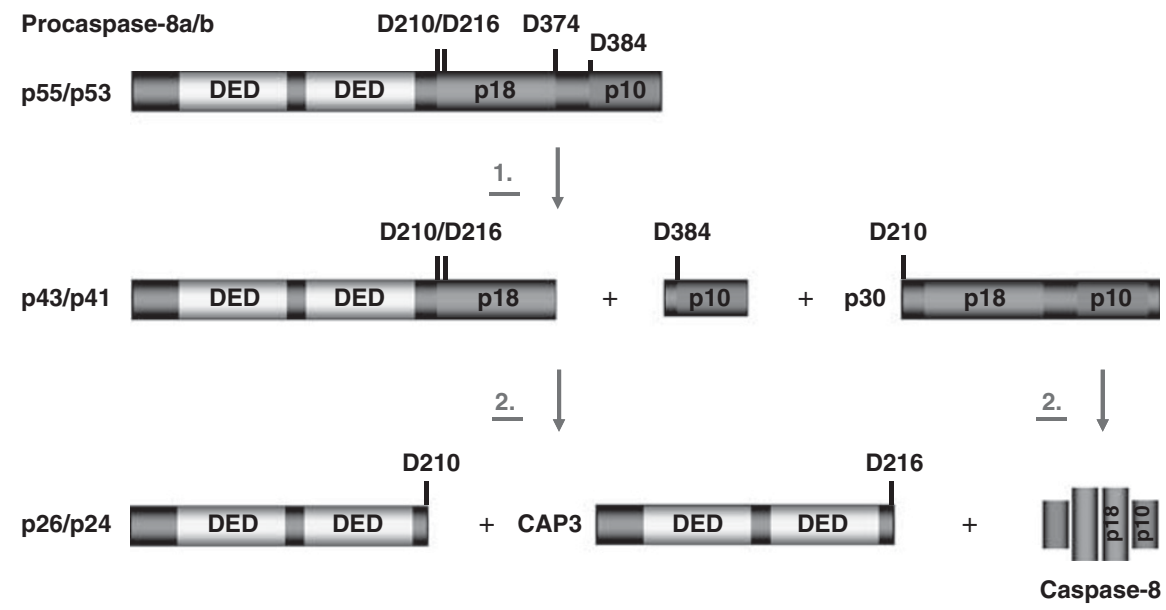

Figure 2 Scheme of procaspase-8 and the two-step mechanism of procaspase-8 activation. Procaspase-8a/b (p55/p53) is shown in green; DEDs are presented in light yellow. The N-terminal cleavage products: p43/p41, prodomains p26/p24, CAP3; C-terminal cleavage product p30 as well as caspase-active domains p18 and p10 are indicated. Two cleavage steps with the resulting products are presented. The color reproduction of this figure is available at the Cell Death and Differentiation journal online

Activation of procaspase-8a/b is believed to occur via oligomerization at the DISC. ${ }^{31-33}$ Procaspase-8a/b was shown to form homodimers at the CD95 DISC, which is a prerequisite for its activation. Furthermore, according to the interdimer model of procaspase- 8 activation, each procaspase-8 homodimer activates another procaspase-8 homodimer. ${ }^{33}$ Hence, the DISC structure provides a platform for the oligomerization of procaspase-8 that allows two procaspase-8 homodimers to be in the close proximity leading to the initial activation of procaspase-8.

The initial activation of procaspase- 8 at the DISC upon dimerization is followed by the subsequent cleavage of procaspase- $8 \mathrm{a} / \mathrm{b}$. This processing occurs at Asp residues located between the prodomain and the large and the small catalytic subunits (Figure 2). ${ }^{30,34}$ We have shown recently that cleavage between the prodomain and the large and the small catalytic subunits occurs simultaneously, though there is a preference towards a cleavage between the large and small catalytic subunits. ${ }^{35}$ This processing results in the generation of a number of the cleavage products, including p43/p41, p26/ p24, CAP3, p30, p18 and p10 (Figure 2). ${ }^{34-37}$ At the first cleavage step, the $\mathrm{N}$-terminal p43/p41 and the C-terminal p30 cleavage products are generated. Importantly, these cleavage products already possess catalytic activity. At the second cleavage step, p43/p41 and p30 are processed to p10 and p18, respectively, which leads to the generation of the active caspase-8 heterotetramer $(\mathrm{p} 18 / \mathrm{p} 10)_{2} \cdot{ }^{38}$ Hence, activation of procaspase- 8 at the DISC is a complex process that involves generation of several catalytically active cleavage products leading to the initiation of apoptosis.

Furthermore, in the course of procaspase- 8 activation at the DISC procaspase-8 undergoes a substrate specificity switch as has been recently shown by Mac Farlane et al. ${ }^{37}$ using in vitro reconstituted DISC. Upon initial dimerization procaspase- 8 at the DISC has a very restricted substrate range, which is limited to itself and c-FLIP. Following cleavage, caspase- 8 is fully activated and can cleave apoptotic substrates, for example caspase- 3 and Bid. The differences in the substrate specificity of procaspase-8 versus caspase-8 have also been demonstrated by other authors using recombinant proteins. ${ }^{33}$ Thus, there are two DISC-mediated caspase- 8 activities: procaspase- 8 activity and 'active caspase- 8 ' activity. The procaspase- 8 activity is required for the initiation of procaspase- 8 processing whereas active caspase-8 induces apoptosis. Furthermore, procaspase-8 activity has been suggested to be indispensible for the initiation of non-apoptotic pathways. ${ }^{37}$ In line with this, it has been recently reported using transgenic mice that the perturbation of the caspase- 8 cleavage site abrogates its pro-apoptotic function without influencing its non-apoptotic function. ${ }^{39}$

Another important mechanism of the regulation of procaspase- 8 activity, which has been discovered recently, is the protein modification of procaspase-8. Phosphorylation of procaspase-8 at the catalytic subunits has been shown to have an important role in the activity of procaspase-8, likely by interfering with processing of procaspase- $8 .{ }^{40}$ Phosphorylation at $Y 380$ of procaspase-8 has been shown to inhibit CD95mediated apoptosis. ${ }^{41}$ In addition, polyubiquitination of procaspase-8 at the DISC has been reported recently to stabilize the active caspase- 8 heterotetramer and, in this way, to have a pro-apoptotic role. ${ }^{42}$ The mechanistic role of protein modifications of procaspase- 8 has to be investigated in more detail in future studies.

In addition to its role in apoptosis there is emerging evidence of the role of procaspase-8 in non-apoptotic signaling pathways and cell survival. Caspase-8 knockout mice are characterized by prenatal lethality and by deficiencies in heart muscle development. ${ }^{43}$ Interestingly, there is a recent report showing that RIP3 knockout can compensate for this effect, providing the evidence for a common signaling pathway mediated by procaspase- 8 and RIP $3 .{ }^{44}$ In addition, the activity of procaspase- 8 has been shown to be essential for the activation of the $\mathrm{NF}-\kappa \mathrm{B}$ signaling pathway during lymphocyte activation. ${ }^{45}$

\section{Cellular FLICE-inhibitory Proteins}

c-FLIP, also known as FLAME-1/I-FLICE/CASPER/CASH/ MRIT/CLARP/Usurpin, is a well-described inhibitor of DRmediated apoptosis. ${ }^{46}$ C-FLIP was first described in 1997 , 

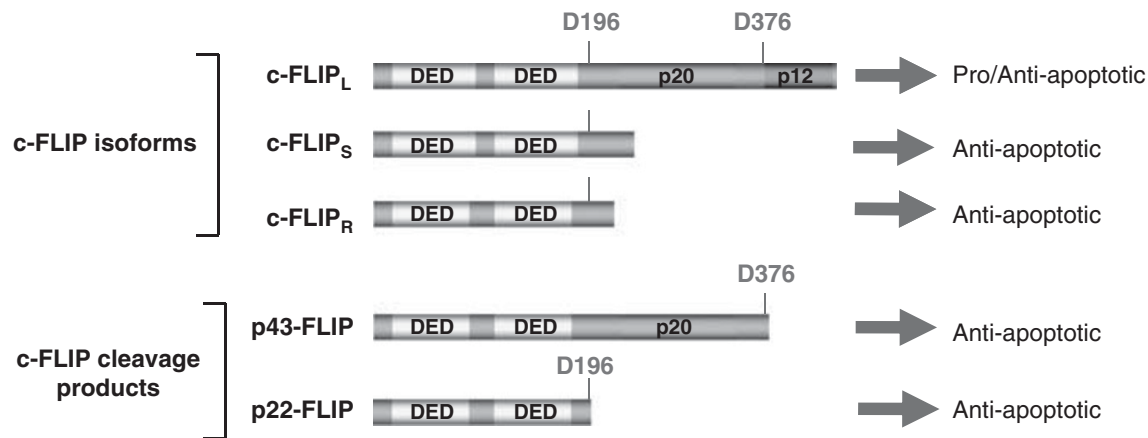

Figure 3 The scheme of c-FLIP proteins. c-FLIP isoforms and c-FLIP cleavage products are shown. DEDs and caspase-like domains (p20 and p12) are indicated. D376 and D196 leading to the generation of p43-FLIP and p22-FLIP, respectively, are presented in red. The color reproduction of this figure is available at the Cell Death and Differentiation journal online

and has been shown to be a major inhibitor of procaspase-8 activation at the DISC. ${ }^{47}$ This finding has been followed by many studies discovering the complexity of DR signaling regulation by $\mathrm{c}$-FLIP proteins and also elucidating the role of $c$-FLIP proteins in NF- $\kappa$ B activation. ${ }^{17,48-52}$ Jürg Tschopp et al. have significantly contributed to the discovery of c-FLIP proteins as well as their role in NF- $\kappa \mathrm{B}$ activation. The current view on c-FLIP proteins is shown in Figure 3. Five c-FLIP proteins have been characterized so far: three c-FLIP isoforms and two cleavage products. ${ }^{17,46,53-56}$

The three c-FLIP isoforms comprise: Long (L), Short (S) and Raji $(R)$, for example c-FLIP ${ }_{L}, c-F L I P S$ and $c-F_{S} P_{R}$, respectively (Figure 3 ). All three isoforms possess two DED domains and thereby bind to the DISC. The short FLIP isoforms, $c-$ FLIP $_{S}$ and $c-$ FLIP $_{R}$, block procaspase-8 activation and apoptosis. ${ }^{52,55} \mathrm{C}-\mathrm{FLIP}_{\mathrm{L}}$ can act as an anti-apoptotic molecule, functioning in a way similar to c-FLIP , when it is present at high concentrations at the DISC. ${ }^{52,57} \mathrm{C}-\mathrm{FLIP}_{\mathrm{L}}$ can also act as a pro-apoptotic molecule. ${ }^{52}$ This occurs upon strong receptor stimulation or in the presence of high amounts of one of the short c-FLIP isoforms, c-FLIP or c-FLIP $_{R}$. Under these conditions $C-F L I P$ promotes the activation of procaspase- 8 at the DISC. ${ }^{52}$

Two cleavage products of c-FLIP have been reported namely p43-FLIP and p22-FLIP. ${ }^{17,56}$ p43-FLIP is generated from C-FLIP $\mathrm{L}_{\mathrm{L}}$ at the CD95 DISC as a result of procaspase-8 cleavage at D376. p22-FLIP is the N-terminal cleavage product of c-FLIP resulting from procaspase- 8 cleavage at D196. In contrast to p43-FLIP, p22-FLIP is formed in the cytosol independently of DR stimulation. In addition, both cleavage products of c-FLIP turned out to be inducers of $\mathrm{NF}-\kappa \mathrm{B}$ activity by binding to the IKK complex. ${ }^{8,56}$

\section{Dynamics of Procaspase-8 and c-FLIP Interactions}

Procaspase-8 and c-FLIP regulate CD95 signaling directly at the DISC (Figure 4). As pointed out above procaspase-8 is activated at the CD95 DISC inducing the apoptotic process. This activation can be inhibited by all reported c-FLIP proteins. The only exception is the $\mathrm{C}-\mathrm{FLIP}_{\mathrm{L}}$ isoform that might also induce procaspase- 8 activation, and might block procaspase8 activation when expressed at high concentrations. Therefore, procaspase- 8 at the DISC has a pro-apoptotic role and

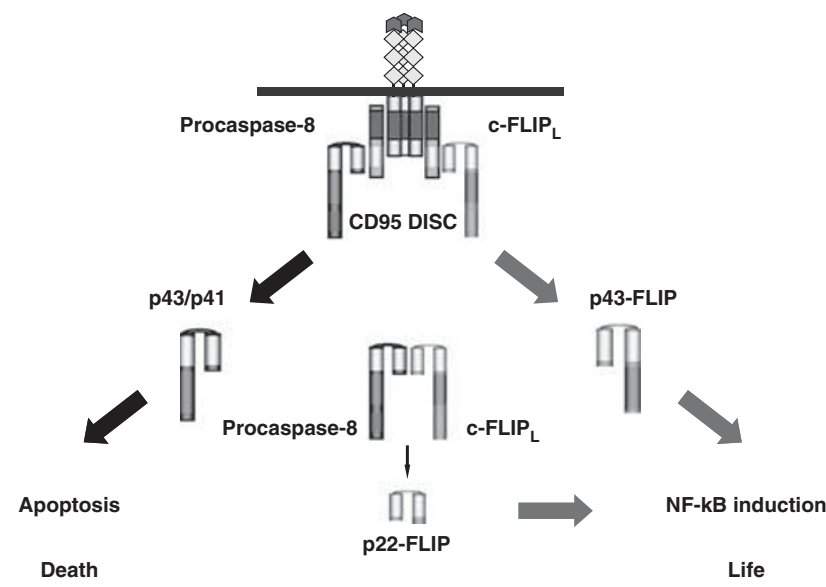

Figure 4 DED proteins: procaspase-8 and c-FLIP at the DISC and in the cytosol. Upon CD95 stimulation the CD95 DISC is formed. Cleavage products of procaspase-8 and c-FLIP,$p 43 / p 41$ and p43-FLIP, respectively, are generated at the DISC. p43/p41 leads to the induction of apoptosis, while p43-FLIP binds to the IKK complex, which results in the induction of NF- $\kappa$ B. Procaspase- 8 and $c-F L I P$ form dimers producing p22-FLIP. p22-FLIP binds to the IKK complex via IKK $\gamma$, which leads to the induction of NF- $\kappa \mathrm{B}$. The color reproduction of this figure is available at the Cell Death and Differentiation journal online

c-FLIP proteins, with the exception of the c-FLIP $\mathrm{L}_{\mathrm{L}}$ isoform, possess an anti-apoptotic function.

In addition to the regulation of apoptosis, it was shown that the main DED-containing proteins of the CD95 DISC, procaspase-8 and c-FLIP, have a prominent role in NF- $\kappa$ B activation. ${ }^{14} \mathrm{c}$-FLIP N-terminal cleavage products $\mathrm{p} 43-\mathrm{FLIP}$ and p22-FLIP strongly induce NF- $\kappa$ B. ${ }^{56,58}$ Procaspase-8 activity is required for generation of these cleavage products.

p43-FLIP is generated by procaspase- 8 at the DISC upon CD95 stimulation. p43-FLIP interacts with components of the TNFR-mediated NF- $\kappa$ B activation pathway, TNFR-associated factor 1 (TRAF1), TRAF2 and RIP, which together promote $\mathrm{NF}-\kappa \mathrm{B}$ activation. ${ }^{58}$ In addition, we have shown that p43-FLIP generated at the DISC might directly activate the IKK complex leading to NF- $\kappa$ B induction (Figure 4$){ }^{8}$

p22-FLIP also induces NF- $\kappa \mathrm{B}$ by direct binding to the IKK complex. ${ }^{56}$ p22-FLIP is generated by procaspase-8 activity in non-apoptotic cells without DR stimulation (Figure 4). ${ }^{56}$ Under these conditions procaspase-8 does not undergo processing leading to apoptosis induction but rather utilizes 
its procaspase activity, which leads to the processing of c-FLIP to the p22-FLIP cleavage product. Procaspase- 8 can induce NF- $\kappa B$ not only via generation of $p 22-F L I P$ or $p 43-$ FLIP, but also by direct binding to the CBM adapter complex formed upon TCR stimulation. ${ }^{45}$ Thus, several studies indicate that the most prominent DED-proteins of the CD95 DISC, procaspase-8 and c-FLIP, have an important role both in CD95-induced apoptotic and non-apoptotic pathways.

This complex interplay between procaspase-8 and c-FLIP leading to the induction of non-apoptotic versus apoptotic pathways has encouraged us to apply a systems biology approach to understand life/death decisions at CD95., 99-61 By using mathematical modeling and experimental data, we have shown that the induction of the apoptotic pathway can be directly connected to the amount of the generated cleavage product $\mathrm{p} 43 / \mathrm{p} 41$ of procaspase-8, whereas the induction of the non-apoptotic pathway depends upon the amount of the generated cleavage product p43-FLIP of $c-$ FLIP $_{\mathrm{L}}{ }^{8}$ The generation of both cleavage products occurs at the CD95 DISC. Furthermore, procaspase- 8 and $\mathrm{c}-\mathrm{FLIP}_{\mathrm{L}}$ compete for the same binding sites at the CD95 DISC. Therefore, the generation of $\mathrm{p} 43-\mathrm{FLIP}$ is non-linear. Upon low concentrations of $c-$ FLIP $_{\mathrm{L}}$ at the DISC, there will be almost no p43-FLIP generated. Upon increase of $C-F L I P L$ amounts, the amount of p43-FLIP produced will be increased. Upon high concentrations of $C-F L I P_{L}$ all binding sites at the DISC will be occupied by $C-F L I P L$ proteins, and this would also block procaspase-8 recruitment and subsequent activation. Consequently, under high c-FLIP overexpression, $C$-FLIP ${ }_{L}$ could not be processed to p43-FLIP at the DISC as procaspase-8 activity at the DISC will be missing. Therefore, a high concentration of $C-F_{L} P_{L}$ would block both apoptotic and non-apoptotic pathways at the DISC. Thus, C-FLIP , depending whether its concentration at the DISC is medium or high, can promote or inhibit CD95-mediated NF- $\kappa$ B activation. ${ }^{8}$ Finally, this analysis show that the regulation of the apoptotic versus non-apoptotic signaling pathways has non-linear dynamics depending on the amount of the generated cleavage products of procaspase-8 or C-FLIP . $_{\text {. }}$

These studies demonstrate that the ratio between DEDcontaining proteins procaspase- 8 and $\mathrm{C}-\mathrm{FLIP}_{\mathrm{L}}$ at the DISC has a major role in the regulation of apoptotic versus nonapoptotic signaling pathways in CD95 signaling. The initiation of CD95-mediated apoptotic and non-apoptotic signals occurs at the DISC and, therefore, the DISC can be considered as the central regulation node of CD95 signaling. Future work should involve a detailed analysis of the stoichiometry of DED proteins at the DISC. The quantitative analysis of the DISC stoichiometry should certainly provide a novel view on the regulation of life and death decisions at the DISC and in DR signaling pathways.

\section{Conflict of Interest}

The authors declare no conflict of interest.

Acknowledgements. We acknowledge the Helmholtz Alliance on Systems Biology (NW1SBCancer/UniHD) and the Helmholtz-Russia Joint Research Groups-2008-2 for supporting our work. We thank Nicolai Fricker, Selcen Öztürk, Kolja Schleich and Claudia Weber for their critical comments.
1. Krammer PH. CD95's deadly mission in the immune system. Nature 2000; 407: 789-795.

2. Tartaglia LA, Ayres TM, Wong GH, Goeddel DV. A novel domain within the $55 \mathrm{kd}$ TNF receptor signals cell death. Cell 1993; 74: 845-853.

3. Weber $\mathrm{CH}$, Vincenz $\mathrm{C}$. The death domain superfamily: A tale of two interfaces? Trends Biochem Sci 2001; 26: 475-481.

4. Suda T, Takahashi T, Golstein P, Nagata S. Molecular cloning and expression of the Fas ligand, a novel member of the tumor necrosis factor family. Cell 1993; 75: 1169-1178.

5. Trauth BC, Klas C, Peters AM, Matzku S, Moller P, Falk W et al. Monoclonal antibodymediated tumor regression by induction of apoptosis. Science 1989; 245: 301-305.

6. Peter ME, Budd RC, Desbarats J, Hedrick SM, Hueber AO, Newell MK et al. The CD95 receptor: apoptosis revisited. Cell 2007; 129: 447-450.

7. Desbarats J, Birge RB, Mimouni-Rongy M, Weinstein DE, Palerme JS, Newell MK. Fas engagement induces neurite growth through ERK activation and p35 upregulation. Nat Cell Biol 2003; 5: 118-125.

8. Neumann L, Pforr C, Beaudouin J, Pappa A, Fricker N, Krammer PH et al. Dynamics within the CD95 death-inducing signaling complex decide life and death of cells. Mol Syst Biol 2010; 6: 352.

9. Lavrik IN, Golks A, Riess D, Bentele M, Eils R, Krammer PH. Analysis of CD95 threshold signaling: triggering of CD95 (FAS/APO-1) at low concentrations primarily results in survival signaling. J Biol Chem 2007; 282: 13664-13671.

10. Demjen D, Klussmann S, Kleber S, Zuliani C, Stieltjes B, Metzger C et al. Neutralization of $\operatorname{CD} 95$ ligand promotes regeneration and functional recovery after spinal cord injury. Nat Med 2004; 10: 389-395.

11. Kleber S, Sancho-Martinez I, Wiestler B, Beisel A, Gieffers C, Hill O et al. Yes and PI3K bind CD95 to signal invasion of glioblastoma. Cancer Cell 2008; 13: 235-248.

12. Zuliani $\mathrm{C}$, Kleber $\mathrm{S}$, Klussmann $\mathrm{S}$, Wenger $\mathrm{T}$, Kenzelmann $\mathrm{M}$, Schreglmann $\mathrm{N}$ et al. Control of neuronal branching by the death receptor CD95 (Fas/Apo-1). Cell Death Differ 2006; 13: 31-40.

13. O'Reilly LA, Tai L, Lee L, Kruse EA, Grabow S, Fairlie WD et al. Membrane-bound Fas ligand only is essential for Fas-induced apoptosis. Nature 2009; 461: 659-663.

14. Krammer PH, Arnold R, Lavrik IN. Life and death in peripheral T cells. Nat Rev Immunol 2007; 7: 532-542.

15. Muzio M, Chinnaiyan AM, Kischkel FC, O'Rourke K, Shevchenko A, Ni J et al. FLICE, a novel FADD-homologous ICE/CED-3-like protease, is recruited to the CD95 (Fas/APO-1) death-inducing signaling complex. Cell 1996; 85: 817-827.

16. Sprick M, Rieser E, Stahl H, Grosse-Wilde A, Weigand M, Walczak H. Caspase-10 is recruited to and activated at the native TRAIL and CD95 death-inducing signalling complexes in a FADD-dependent manner but can not functionally substitute caspase-8. EMBO J 2002; 21: 4520-4530.

17. Scaffidi C, Schmitz I, Krammer PH, Peter ME. The role of C-FLIP in modulation of CD95induced apoptosis. J Biol Chem 1999; 274: 1541-1548.

18. Siegel RM, Frederiksen JK, Zacharias DA, Chan FK, Johnson M, Lynch D et al. Fas preassociation required for apoptosis signaling and dominant inhibition by pathogenic mutations [see comments]. Science 2000; 288: 2354-2357.

19. Scott FL, Stec B, Pop C, Dobaczewska MK, Lee JJ, Monosov E et al. The Fas-FADD death domain complex structure unravels signalling by receptor clustering. Nature 2009; 457: 1019-1022.

20. Wang L, Yang JK, Kabaleeswaran V, Rice AJ, Cruz AC, Park AY et al. The Fas-FADD death domain complex structure reveals the basis of DISC assembly and disease mutations. Nat Struct Mol Biol 2010; 17: 1324-1329.

21. Scaffidi C, Fulda S, Srinivasan A, Friesen C, Li F, Tomaselli KJ et al. Two CD95 (APO-1/ Fas) signaling pathways. EMBO J 1998; 17: 1675-1687.

22. Yin XM, Wang K, Gross A, Zhao Y, Zinkel S, Klocke B et al. Bid-deficient mice are resistant to Fas-induced hepatocellular apoptosis. Nature 1999; 400: 886-891.

23. Kaufmann T, Tai L, Ekert PG, Huang DC, Norris F, Lindemann RK et al. The BH3-only protein bid is dispensable for DNA damage- and replicative stress-induced apoptosis or cell-cycle arrest. Cell 2007; 129: 423-433.

24. Jost PJ, Grabow S, Gray D, McKenzie MD, Nachbur U, Huang DC et al. XIAP discriminates between type I and type II FAS-induced apoptosis. Nature 2009; 460: 1035-1039.

25. Lavrik IN, Mock T, Golks A, Hoffmann JC, Baumann S, Krammer PH. CD95 stimulation results in the formation of a novel death effector domain protein-containing complex. J Biol Chem 2008; 283: 26401-26408.

26. Geserick P, Hupe M, Moulin M, Wong WW, Feoktistova M, Kellert B et al. Cellular IAPs inhibit a cryptic CD95-induced cell death by limiting RIP1 kinase recruitment. J Cell Biol 2009; 187: 1037-1054.

27. Micheau O, Tschopp J. Induction of TNF receptor I-mediated apoptosis via two sequential signaling complexes. Cell 2003; 114: 181-190.

28. Varfolomeev E, Maecker H, Sharp D, Lawrence D, Renz M, Vucic D et al. Molecular determinants of kinase pathway activation by Apo2 ligand/tumor necrosis factor-related apoptosis-inducing ligand. J Biol Chem 2005; 280: 40599-40608.

29. Medema JP, Scaffidi C, Kischkel FC, Shevchenko A, Mann M, Krammer PH et al. FLICE is activated by association with the CD95 death-inducing signaling complex (DISC). EMBO J 1997; 16: 2794-2804.

30. Scaffidi C, Medema JP, Krammer PH, Peter ME. FLICE is predominantly expressed as two functionally active isoforms, caspase-8/a and caspase-8/b. J Biol Chem 1997; 272: 26953-26958. 
31. Muzio M, Stockwell BR, Stennicke HR, Salvesen GS, Dixit VM. An induced proximity model for caspase-8 activation. J Biol Chem 1998; 273: 2926-2930.

32. Pop C, Fitzgerald P, Green DR, Salvesen GS. Role of proteolysis in caspase-8 activation and stabilization. Biochemistry 2007; 46: 4398-4407.

33. Chang DW, Xing Z, Capacio VL, Peter ME, Yang X. Interdimer processing mechanism of procaspase-8 activation. EMBO J 2003; 22: 4132-4142.

34. Golks A, Brenner D, Schmitz I, Watzl C, Krueger A, Krammer PH et al. The role of CAP3 in CD95 signaling: new insights into the mechanism of procaspase-8 activation. Cell Death Differ 2006; 13: 489-498.

35. Hoffmann JC, Pappa A, Krammer PH, Lavrik IN. A new C-terminal cleavage product of procaspase-8, p30, defines an alternative pathway of procaspase-8 activation. $\mathrm{Mol} \mathrm{Cell}$ Biol 2009; 29: 4431-4440.

36. Lavrik IN, Golks A, Krammer PH. Caspases: pharmacological manipulation of cell death $J$ Clin Invest 2005; 115: 2665-2672.

37. Hughes MA, Harper N, Butterworth M, Cain K, Cohen GM, MacFarlane M. Reconstitution of the death-inducing signaling complex reveals a substrate switch that determines CD95mediated death or survival. Mol Cell 2009; 35: 265-279.

38. Lavrik I, Krueger A, Schmitz I, Baumann S, Weyd H, Krammer PH et al. The active caspase-8 heterotetramer is formed at the CD95 DISC. Cell Death Differ 2003; 10: 144-145

39. Kang TB, Oh GS, Scandella E, Bolinger B, Ludewig B, Kovalenko A et al. Mutation of a self-processing site in caspase-8 compromises its apoptotic but not its nonapoptotic functions in bacterial artificial chromosome-transgenic mice. $J$ Immunol 2008; 181: 2522-2532.

40. Matthess Y, Raab M, Sanhaji M, Lavrik IN, Strebhardt K. Cdk1/cyclin B1 controls Fas mediated apoptosis by regulating caspase-8 activity. Mol Cell Biol 2010; 30: 5726-5740.

41. Cursi S, Rufini A, Stagni V, Condo I, Matafora V, Bachi A et al. Src kinase phosphorylates Caspase-8 on Tyr380: a novel mechanism of apoptosis suppression. EMBO J 2006; 25 1895-1905.

42. Jin Z, Li Y, Pitti R, Lawrence D, Pham VC, Lill JR et al. Cullin3-based polyubiquitination and p62-dependent aggregation of caspase-8 mediate extrinsic apoptosis signaling. Cell 2009; 137: 721-735.

43. Varfolomeev EE, Schuchmann M, Luria V, Chiannilkulchai N, Beckmann JS, Mett IL et al. Targeted disruption of the mouse Caspase 8 gene ablates cell death induction by the TNF receptors, Fas/Apo1, and DR3 and is lethal prenatally. Immunity 1998; 9: 267-276.

44. Kaiser WJ, Upton JW, Long AB, Livingston-Rosanoff D, Daley-Bauer LP, Hakem R et al. RIP3 mediates the embryonic lethality of caspase-8-deficient mice. Nature 2011; 471 : 368-372.

45. Su H, Bidere N, Zheng L, Cubre A, Sakai K, Dale J et al. Requirement for caspase-8 in NFkappaB activation by antigen receptor. Science 2005; 307: 1465-1468.
46. Budd RC, Yeh WC, Tschopp J. cFLIP regulation of lymphocyte activation and development. Nat Rev Immunol 2006; 6: 196-204.

47. Irmler M, Thome M, Hahne M, Schneider P, Hofmann K, Steiner V et al. Inhibition of death receptor signals by cellular FLIP. Nature 1997; 388: 190-195.

48. Micheau O, Thome M, Schneider P, Holler N, Tschopp J, Nicholson DW et al. The long form of FLIP is an activator of caspase-8 at the Fas death-inducing signaling complex. J Biol Chem 2002; 277: 45162-45171.

49. Tschopp J, Irmler M, Thome M. Inhibition of fas death signals by FLIPs. Curr Opin Immunol 1998; 10: 552-558.

50. Dohrman A, Kataoka T, Cuenin S, Russell JQ, Tschopp J, Budd RC. Cellular FLIP (long form) regulates CD8(+) T cell activation through caspase-8-dependent NF-kappa B activation. J Immunol 2005; 174: 5270-5278.

51. Kataoka T, Budd RC, Holler N, Thome M, Martinon F, Irmler M et al. (2000 The caspase-8 inhibitor FLIP promotes activation of NF-kappaB and Erk signaling pathways. Curr Biol 10: 640-648

52. Fricker N, Beaudouin J, Richter P, Eils R, Krammer PH, Lavrik IN. Model-based dissection of CD95 signaling dynamics reveals both a pro- and antiapoptotic role of c-FLIPL. J Cell Biol 2010; 190: 377-389.

53. Thome M, Schneider P, Hofmann K, Fickenscher H, Meinl E, Neipel F et al. Viral FLICEinhibitory proteins (FLIPs) prevent apoptosis induced by death receptors. Nature 1997; 386: 517-521.

54. Krueger A, Baumann S, Krammer PH, Kirchhoff S. FLICE-inhibitory proteins: regulators of death receptor-mediated apoptosis. Mol Cell Biol 2001; 21: 8247-8254.

55. Golks A, Brenner D, Fritsch C, Krammer PH, Lavrik IN. c-FLIPR, a new regulator of death receptor-induced apoptosis. J Biol Chem 2005; 280: 14507-14513.

56. Golks A, Brenner D, Krammer PH, Lavrik IN. The c-FLIP-NH2 terminus (p22-FLIP) induces NF-kappa B activation. J Exp Med 2006; 203: 1295-1305

57. Krueger A, Schmitz I, Baumann S, Krammer PH, Kirchhoff S (2001 Cellular flice-inhibitory protein splice variants inhibit different steps of caspase-8 activation at the cd95 deathinducing signaling complex. J Biol Chem 276: 20633-20640.

58. Kataoka T, Tschopp J. N-terminal fragment of $c-F L I P(L)$ processed by caspase 8 specifically interacts with TRAF2 and induces activation of the NF-kappaB signaling pathway. Mol Cell Biol 2004; 24: 2627-2636.

59. Bentele M, Lavrik I, Ulrich M, Stosser S, Heermann DW, Kalthoff $\mathrm{H}$ et al. Mathematical modeling reveals threshold mechanism in CD95-induced apoptosis. J Cell Biol 2004; 166: 839-851.

60. Lavrik IN, Eils R, Fricker N, Pforr C, Krammer PH. Understanding apoptosis by systems biology approaches. Mol Biosyst 2009; 5: 1105-1111.

61. Lavrik IN. Systems biology of apoptosis signaling networks. Curr Opin Biotechnol 2010; 21 551-555. 